\title{
An experiment to check the accuracy of non-destructive surface electrical resistivity technique in delineation of foundation beds within $5 \mathrm{~m}$ from ground surface
}

\author{
Muhammad Younis Khan \\ Division of Geophysics, National Centre of Excellence in Geology, University of Peshawar, Pakistan
}

\begin{abstract}
A shallow sub-surface electrical resistivity survey (ERS) was carried out at Shaukat Khanum Memorial Cancer Hospital and Research Centre (SKMCH\&RC), Peshawar, Pakistan. The main objective of the survey was to capture a clearer picture of the near-surface geologic sequence to study geophysically the attributes (depth \& thickness) indirectly of particular horizon lying within five meters beneath the earth's surface for an engineering study supported by actual values (bore hole data and measured values at field). Vertical electrical sounding (VES) data was acquired using Shlumberger configuration with maximum current electrodes separation (ABmax) of 16 feet in order to resolve clearly the target geoelectric layer in the very immediate vicinity of exposed geologic cross section of an excavation designed for construction of basement of massive civil structure (SKMCH\&RC). Geophysical electrical resistivity technique mapped the particular layer's depth and associated thickness having values of $4.42 \mathrm{~m}$ and $2.87 \mathrm{~m}$ respectively. VES results (depth \& thickness) were validated by the actual field values obtained from measuring tape as well as borehole information of the studied site. Comparison showed that geophysical electrical survey technique imaged the target geologic layer accurately with uncertainty of 0.3 feet only. This study deduced the presence of inhomogeneous near-surface media covering the depth range $(<1-5 m)$ where building foundations are usually placed. The error of 0.3 feet in estimation of both parameters guarantees the successful applicability of said geophysical tool in near-surface engineering geophysical investigations with high accuracy in nondestructive, cost effective and faster way. One of the objectives of the study was to introduce ERS technique and encourage utilization of other geophysical tools for such sort of engineering works at Pakistan to avoid any geotechnical hazard.
\end{abstract}

Keywords: Depth \& thickness, Electrical resistivity survey (ERS), Foundation bed, geotechnical hazard, Shallow sub-surface, Vertical electrical sounding (VES), Khyber Pakhtunkhwa, Pakistan.

\section{INTRODUCTION}

The use of geophysics for engineering investigations has increased due to the rapid advances in instrumentation and sophisticated computer software packages. In electrical resistivity techniques known direct current is introduced into the ground through a pair of current electrodes (potential electrodes (MN) on the surface are used to record the resultant potential difference between them [1], giving us a way to measure the apparent resistivity $(\Omega \mathrm{m})$, which is then a function of the geometry and spacing of the surface electrodes (current \& potential), the introduced current and the voltage response. The apparent resistivity (pa) is given by equation (1)

$\mathrm{pa}=\mathrm{KV} / \mathrm{I}$

Where $\mathrm{K}$ denotes a geometric coefficient dependent upon the electrode array, V denotes the measured potential difference and I denotes the current intensity.

The geophysical resistivity survey is used to measure the electrical resistivity, thickness, depth of the geoelctric layers and widely applied in engineering and environmental applications [2], [3], [4], [5] and [6] .According to [7], there are two modes normally used for electrical resistivity data acquisition

1: VES (vertical electrical sounding): In this mode current potential electrodes have constant separation and electrodes are moved along certain direction to determine vertical variation in resistivity.

2: CST (constant separation traversing): In this mode current and potential electrodes have constant separation and are moved along certain direction to determine the lateral variation in resistivity.

This paper is focused at investigating the depth and thickness of subsurface lithology at Shaukat Khanum Memorial Cancer Hospital and Research Centre (SKMCH\&RC), Peshawar, Pakistan, geophysically with the intention of testing the accuracy and introducing a rapid, non-destructive, reliable and economical method in market at Pakistan for civil works providing critical information about depth, thickness and nature of sub-soil conditions. We expect that such small piece of research work from academia side could possibly be used as a working guide towards setting up of appropriate platforms/industries/firms providing geophysical services as well as to convince the investors and encourage the application of all geophysical techniques 
including ERS to resolve geotechnical ,environmental and hydro-geophysical problems faced by the society in industrialized or densely populated growing capital cities like Peshawar, where such type of practice totally ignored except mega projects in civil sector .

\section{GeOlOGiCAl SetTing}

Peshawar basin is an intermountain basin lying at southern margin of Pakistani Himalayas surrounded by mountain ranges of Khyber in the west and north west, Swat in the north east the Attock-Cherat in south while its southern-eastern border is bordered by Indus River. Peshawar basin is mainly covered by sediments of Pleistocene to recent age, characterized as flood plain and lacustrine/loess sediments [8] , [9].Three main rivers (Indus, Kabul and Swat) deposit sand, gravel and clay being transported over long distances from their source locations.

The study area (Shaukat Khanum Memorial Cancer Hospital and Research Centre (SKMCH\&RC), Peshawar) is located in the Peshawar basin as shown in the Fig. 1.

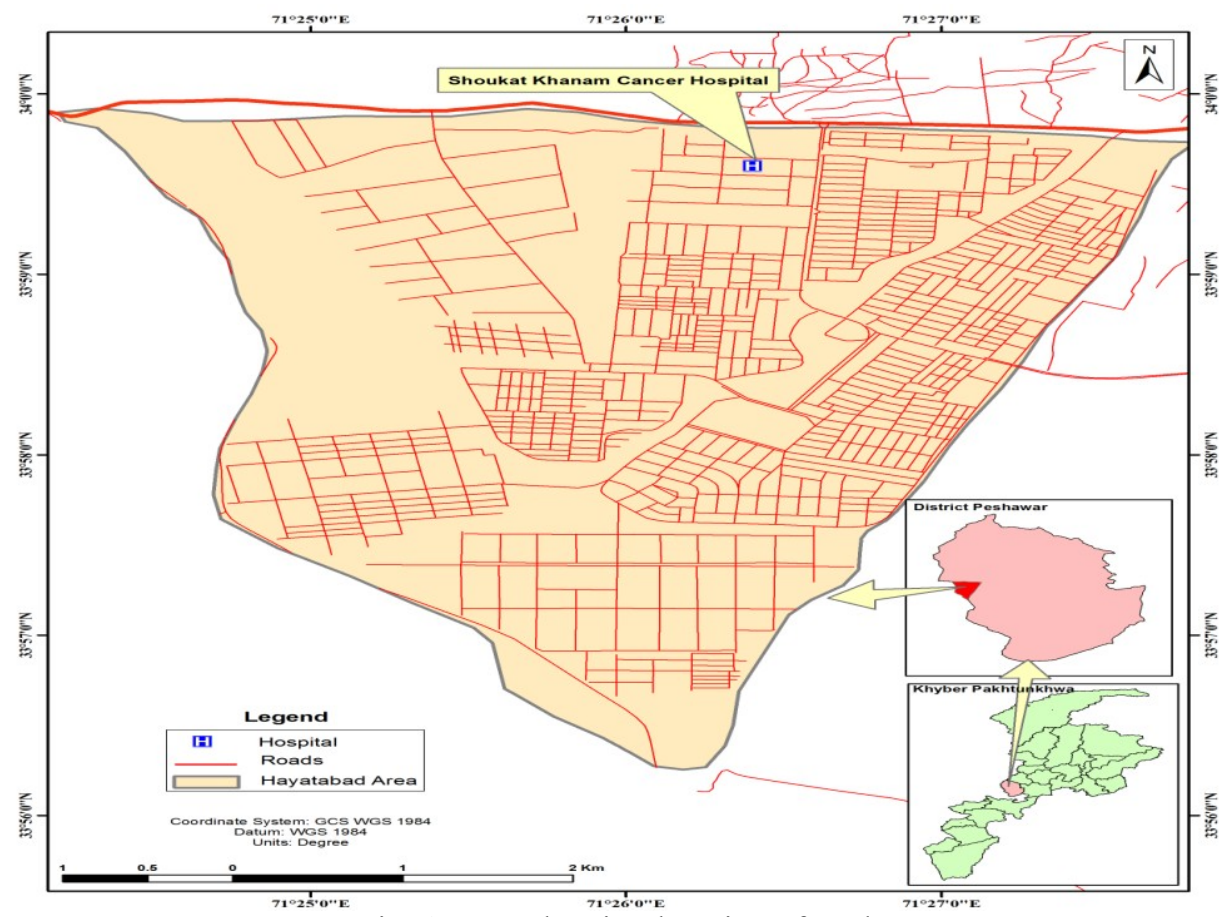

Fig. 1: Map showing location of study area

\section{METHODOLOGY}

Vertical electrical sounding (VES) method is effective in investigating horizontally deposited subsurface media. Therefore geoelectric resistivity survey was conducted based on vertical electrical soundings (VES) using Schlumberger configuration with $\mathrm{MN}=2 \mathrm{~b}$ and $1 / 2 \mathrm{AB}=\mathrm{L}$. The main instrument used to carry out the measurements is the ABEM (SAS 4000/1000) Terrameter. Basic parameters of VES survey and instrument description are given in Table 1\& Fig. 2 respectively. First the geometric factor, K, was calculated using the simple mathematical equation (2)

$\mathrm{K}=\pi(\mathrm{L} 2 / 2 \mathrm{~b}-\mathrm{b} / 2)$.

The values obtained, were then multiplied with the resistance values to obtain the apparent resistivity automatically by the geophysical unit. The apparent resistivity values at every single VES point were displayed on the SAS 4000/1000 resistivity meter's digital screen and then noted down on specific paper (VES field data sheet). 


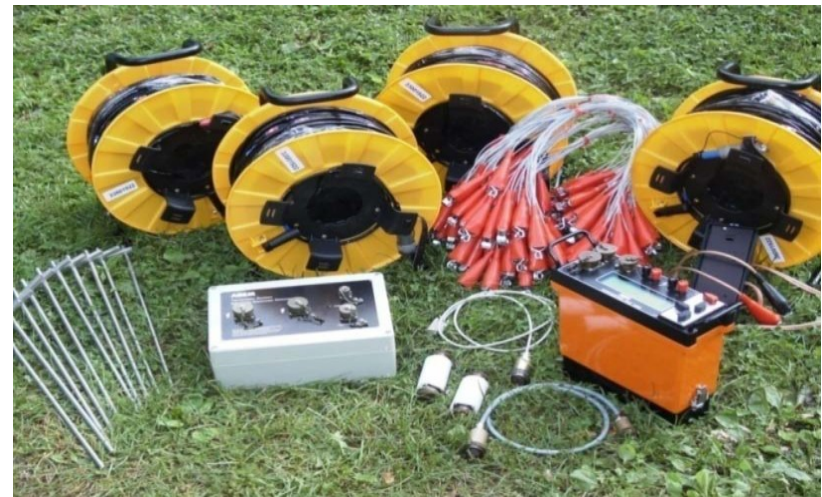

Fig. 2: SAS 1000/4000 Terrameter unit used for electrical resistivity survey (ERS) consisting of electrodes, electrode cables and control unit

Table 1: Summary of electrical resistivity survey (ERS) acquisition parameters

\begin{tabular}{|c|c|}
\hline Recording system & ABEM Terrameter (SAS 1000/4000) \\
\hline Configuration type & Shlumberger \\
\hline Mode of survey & VES (vertical electrical sounding) \\
\hline Maximum electrode separation & 16 feet \\
\hline Profile interval & 1 feet \\
\hline
\end{tabular}

\section{INTERPRETATION/CONCLUSIONS}

The data was imported to a computer software IPI2win .Then the apparent resistivity, $\rho$ a, values were plotted on $\mathrm{Y}$-axis while the electrode spacing $(\mathrm{AB})$ on $\mathrm{X}$-axis using a double logarithmic scale to construct the VES sounding curves. The geoelectric variables e.g. resistivity, depth and thickness of sub-surface layers are obtained, showing RMS error of $1.5 \%$. VES data was acquired in very surrounding of the excavation with current electrodes spaced at 1 feet to clearly image the shallow sub-surface to be correlated and validated by measuring tape. The interpreted VES curve (Fig. 3) showed that surveyed area composed of three layers. Details of which are given in Table 2.First geoelectric layer having resistivity value of $54.9 \Omega \mathrm{m}$ interpreted as surface material. We were interested in precise estimation of depth and thickness of the second layer characterized by gravely clay to unsaturated gravel with resistivity value of $1478 \Omega \mathrm{m}$ going from top to bottom in the photograph at the studied site reflecting field conditions. It is clear from the interpreted VES curve that second layer in the area appeared at approximately $4.35 \mathrm{~m}$ depth from ground surface with $2.87 \mathrm{~m}$ thickness. To check the accuracy of ERS, depth and thickness were measured by a measuring tape from the earth's surface on the top of exposed geological succession. The measured depth was $4.419 \mathrm{~m}$ as shown in the Fig. 4.

A difference of approximately 0.30 feet was observed upon comparison between calculated and measured values of the geoelectric parameters of the target horizon. These parameters need to be determined with high precision and must be considered seriously while dealing with construction of high rise plazas and multi storey buildings due to heterogeneous nature and incompetent strata host by shallow sub-surface media. Very rarely feasibility studies are conducted in Pakistan except some mega projects funded by government which has caused several times serious damage to the engineering structures and thus put human life on risk due to the existence of incompetent strata in sub-surface as observed in this research work represented by overlying and underlying strata having low resistivity values of $54.9 \Omega \mathrm{m}$ and $20.2 \Omega \mathrm{m}$ respectively.

The aforementioned site was selected for the test purpose as civil work is in progress for construction of gigantic structure with a basement and multi storey buildings will be available facilitating people to fight against cancer. Also it was a great opportunity to verify the VES modeling results by correlating them with the actual geological conditions exposed in the excavation. Therefore this investigation presents some results typically obtained for an engineering project in the study area. Very small difference of fraction of feet in this case study increased our confidence level in assuming that surface electrical resistivity technique can provide us with accurate results in non-destructive and cost effective way for shallow sub-surface engineering applications. The interpreted geoelerictric VES curve show good correlation with exposed geologic section clearly shown in photograph as given in the Fig. 4 obtained from excavated portion, prepared for the construction of basement at Shaukat Khanum Memorial Cancer Hospital and Research Centre (SKMCH\&RC), Peshawar, Pakistan.

Usually VES data is collected along several profiles to confirm the results but here we used only one VES station data due to availability of exposed geologic sequence in excavation as well as borehole information to validate the geophysical results of the studied site. 
Table 2: The Summary of the interpreted VES curve

\begin{tabular}{|c|c|c|c|c|}
\hline \# VES /Location & $\mathrm{N}$ (\# layers) & $\rho(\Omega \mathrm{m})$ & $\mathrm{h}(\mathrm{m})$ & $\mathrm{d}(\mathrm{m})$ \\
\hline 1 & 3 & 54.9 & 1.48 & 1.48 \\
\hline & & 1478 & 2.87 & 4.35 \\
\hline
\end{tabular}

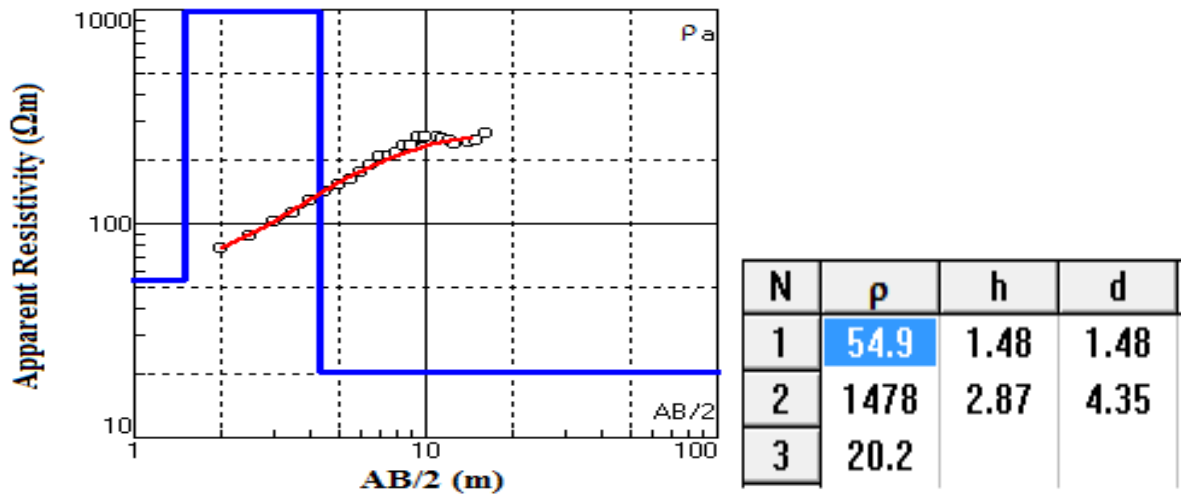

Fig. 3: Interpreted VES curves underneath VES1

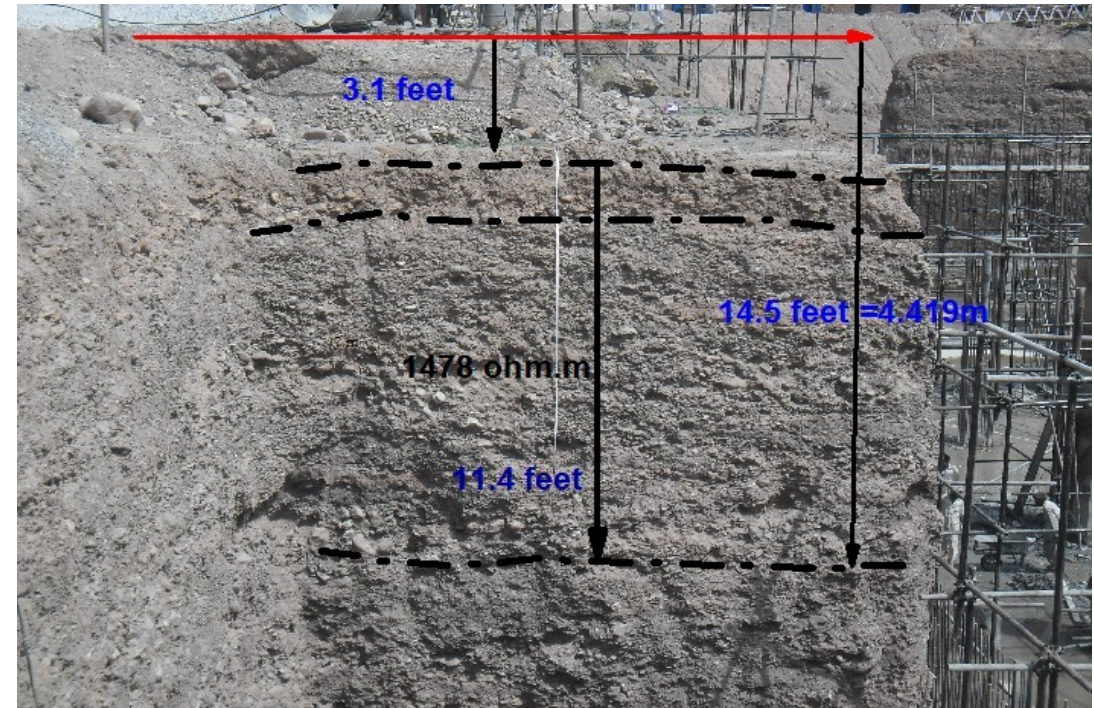

Fig. 4: Interpreted geologic cross section exposed in excavation underneath VES1

\section{REFERENCES}

[1] W.M. Telford, L. P. Geldart, R. E. Sheriff and Keys, D. A, Applied geophysics (UK, Cambridge University Press, 1976)

[2] D.H. Griffiths and R. F. King, Applied geophysics for Engineering and geologists (Oxford, Pergamon Press, 1965).

[3] M.B. Dobrin, Introduction to geophysical prospecting (New York, McGraw- Hill, 1976).

[4] H.R. Burger, Exploration geophysics of the shallow subsurface (New Jersey, Prentice Hall, 1992).

[5] P.V. Sharma, Environmental and engineering geophysics (UK, Cambridge University Press, 1997).

[6] M.Y. Khan, Engineering geophysical study of unconsolidated top soil using shallow seismic refraction and electrical resistivity techniques, Journal of Environment and Earth Science, 3(8), 2013, 120-127.

[7] J.M. Reynolds, An introduction to applied and environmental geophysics (UK, John Wiley \& Sons Ltd, 1997).

[8] D.W. Burbank and R.A.K. Tahirkheli, The magnetostratigraphy, fission track dating, and stratigraphic evolution of the Peshawar intermountain basin, northern Pakistan, Geological Society of America Bulletin, 96, 1985, 539-552.

[9] K. Cornwell, S. Hamidullah, Geomorphic evidence of catastrophic flooding along the middle Indus valley, Geological bulletin, University of Peshawar, 25, 1992, 113-121. 